\title{
NUMERICAL MODELING AND PREDICTION OF WELD MICROSTRUCTURE IN HIGH-STRENGTH STEEL WELDING (REVIEW)
}

\author{
D.Yu. ERMOLENKO and V.V. GOLOVKO \\ E.O. Paton Electric Welding Institute, NASU \\ 11 Bozhenko Str., 03680, Kiev, Ukraine. E-mail: office@paton.kiev.ua
}

\begin{abstract}
Analysis of state-of-the-art of problems of numerical modeling and prediction of weld metal microstructure in high-strength low-alloyed steels was performed. Modern approaches to computer modeling of weld microstructure are analyzed from the viewpoint of prediction of weld metal microstructure and properties, taking into account the influence of nonmetallic inclusions on them. General principles of the problem of modeling the process of formation and evolution of nonmetallic inclusions in the weld metal are considered. Thermodynamic approach to prediction of weld metal microstructure and its drawbacks are presented. Features of modeling the process of metal solidification in the weld pool have been analyzed. Theoretical models of dendrite growth by Ivantsov and KGT-theory are noted; limitations of analytical modeling are described. Critical analysis of numerical models of dendrite solidification has been performed. A conclusion was made that the most adequate and experimentally substantiated results of dendrite growth modeling, allowing for nonmetallic inclusion influence, are to be expected from the method of cellular automation, which should be modified allowing for the capabilities of analytical and numerical models. Such an approach is based to computational simplicity and no need for determination of a number of physical constants for real materials. 53 Ref., 3 Figures.
\end{abstract}

$\boldsymbol{K} \boldsymbol{e} \boldsymbol{y} \boldsymbol{w} \boldsymbol{o r d s}:$ weld, microstructure, primary structure, dendrites, nonmetallic inclusions, numerical modeling, microstructure prediction

The main objective in selection of welding technology and welding consumables is the ability to influence weld metal microstructure formation through selection of the welding process, variation of its parameters and weld metal composition [1, 2].

Process of formation of weld metal microstructure is of a pronounced hereditary nature. Secondary microstructure which ensures higher values of weld performance, inherits certain parameters of primary structure, forming as a result of epitaxial growth of dendrites.

Let us consider a schematic (Figure 1), which generalizes modern trends in modeling weld metal structure formation [3, 4]. Modeling of the process of formation of welded joint metal structure is divided into two main groups - macroand micromodeling.

Let us briefly consider currently available models, describing the influence of each of these factors on structure formation on microlevel.

Models of nonmetallic inclusion formation. Inclusions form in welds as a result of interaction of dissolved aluminium, titanium, silicon and manganese with oxygen, nitrogen, carbon and sulphur. Inclusions are characterized by the vol- ume fraction, size, composition, morphology and further solid-phase transformation. For instance, inclusions, containing a large amount of titanium in the surface layer, promote formation of acicular ferrite $[5,6]$.

In work [7] K.C. Hseih described the thermodynamics of nonmetallic inclusion formation in the temperature range from 2300 to $1800 \mathrm{~K}$ and showed that both simple and complex oxides form at different temperatures. A similar approach was used also in [8] by T. Koseki. The model describing the kinetics of reaction of simultaneous formation of oxides, according to which the oxide content, their morphology and formation temperature change, depending on the composition of molten weld metal, is given in $[9,10]$.

These data allow for the features of nonmetallic inclusion formation, but do not in any way take into account their influence, either on solidification front movement in the weld pool, or on the morphology and dimensions of weld metal components.

Thermodynamic and kinetic models based on phase diagrams. Such models are based on the method of CALculation of PHAse Diagrams (CALPHAD) [11]. CALPHAD technique allows using an extensive base of accessible thermochemical data (thermodynamic and phase equilibrium data) to select model parameters and de- 


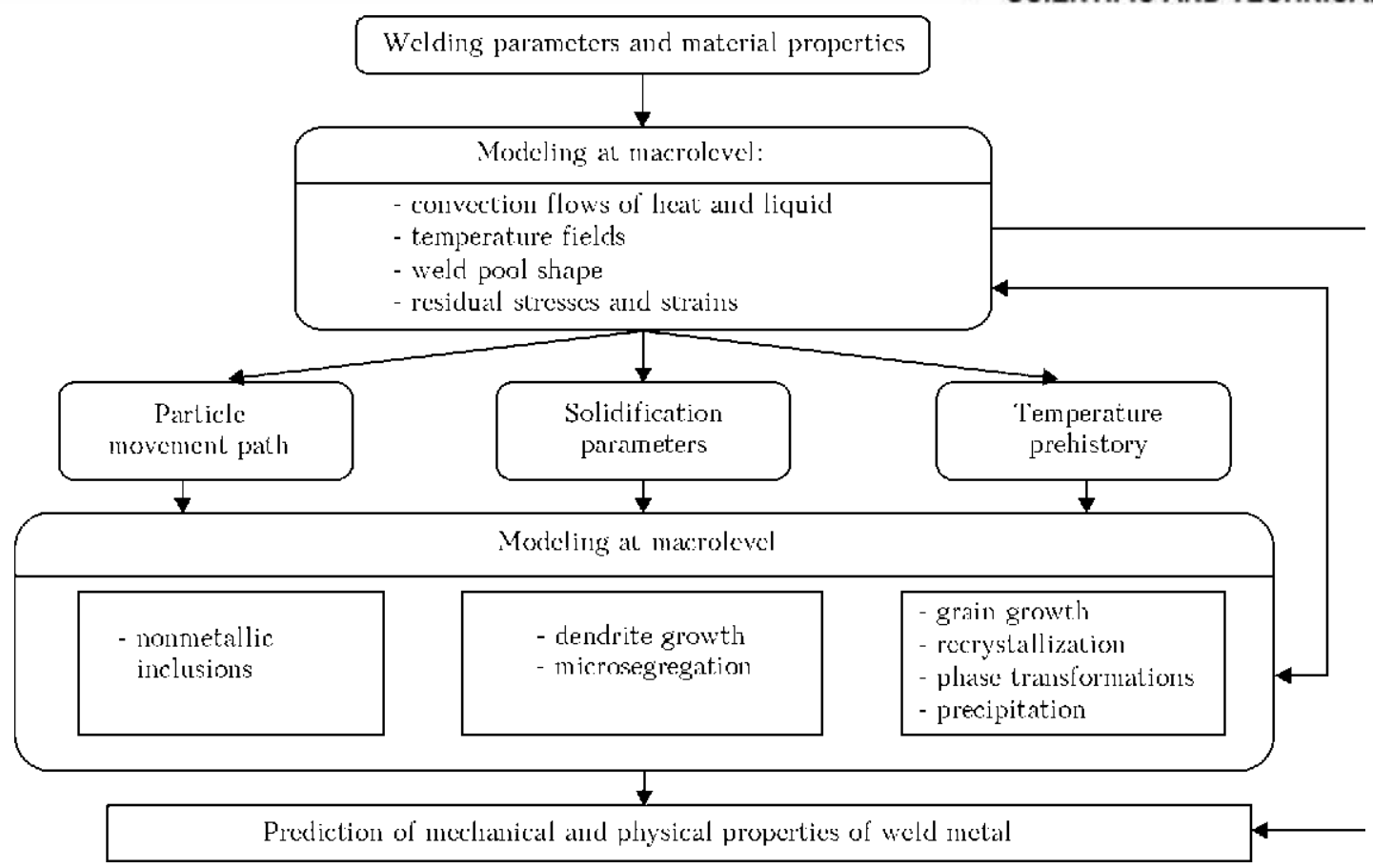

Figure 1. Schematic of weld metal structure modeling

scribe Gibbs energy of individual crystallographic phases. Gibbs energy of each phase is described by the respective thermodynamic model and depends on physical and chemical properties of the phase. These Gibbs energy functions, allowing for composition and temperature dependence, were derived by critical assessment of binary and ternary diagrams, and then were precised, using Thermo-Calc software [12]. The main disadvantage of thermodynamic models is the impossibility of allowing for process kinetics that is quite urgent in the case of weld solidification.

Kinetic models, based on diffusion-controlled growth, can be integrated with thermodynamic models to obtain valuable data on microstructural evolution [13]. They can be used to calculate the influence of cooling rate on final weld microstructure.

Models of this type can be used only in the case of availability of certain phase diagrams in the data base. Construction of new diagrams requires a large scope of experimental work. Moreover, these models cannot allow for the influence of nonmetallic inclusions on formation of microstructural components.

Modeling solid-phase transformations during cooling. Final weld microstructure forms as a result of solid-phase transformations at metal cooling from solidus to room temperature.

The best known tools were developed by A. Schaeffler and modified in the form of WRC1992-diagrams. In the following years new methods were developed. One of them [14] is based on comparison of thermodynamic stability of fer- rite and austenite and is comparable to WRC1992-diagrams in terms of accuracy, although it can be applied to a broader alloy range. $40 \%$ more accurate results that those of WRC-1992diagrams are given by an approach based on neural network [15].

In the case of low-alloyed steels, weld microstructure can be predicted using Bhadeshia models, considered in [16]. They, however, do not take into account the hereditary nature of formation of final weld microstructure, as they consider only austenite grain transformation. HAZ metal structure can be modeled using Ashby model [17], complementing the classical works by N. Yurioka [18].

These models are capable of prediction of quantitative ratio of phases in the weld metal final structure, proceeding from the composition and cooling rate of weld metal, but do not provide any information on the influence of nonmetallic inclusions on the process of its formation. In order to exactly understand weld metal structure evolution during cooling and determine the influence of inclusions on primary solidification front movement, it is necessary to consider weld pool metal solidification as a process of liquid phase transition into solid phase.

Metal solidification in the weld pool. Conditions of metal solidification determine the structure, homogeneity and strength of cast products as a whole. Knowledge of solidification processes in regular metal casting is directly related to fusion welding processes, which can be regarded as «casting in miniature» [19]. 


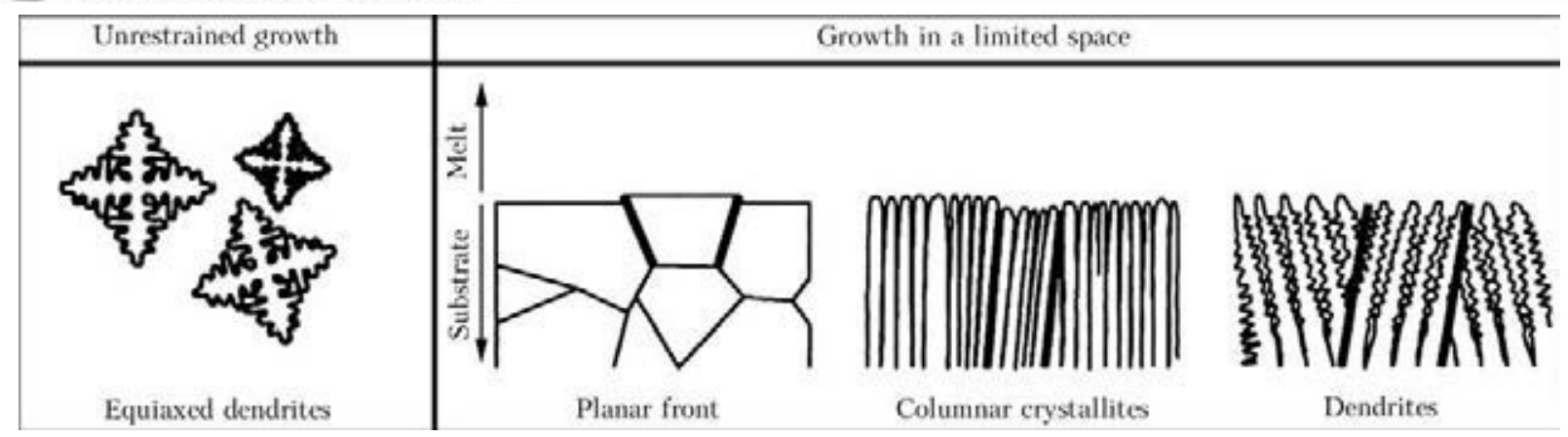

Figure 2. Possible solidification morphologies of weld metal [20]

Process of metal solidification in the weld pool controls grain size and shape, weld defectiveness (porosity and hot cracks). There is some similarity between ingot crystallization and weld pool solidification, but modeling melt solidification in the weld zone is made more complicated by such factors as [1]:

- dynamic nature of the welding process;

- indeterminateness of weld pool shape;

- epitaxial growth (crystal growth on the substrate and, consequently, inheriting the substrate crystallographic orientation);

- change of temperature gradient and rate in different portions of weld pool.

At alloy solidification, two variants of solidification are possible depending on cooling rate, which differ by the method of heat removal from solidification surface [20]:

- unrestrained growth in overcooled melt; in such a case equiaxed dendrites mostly form;

- directional solidification or growth in a limited space; in such a case, flat, columnar or dendritic structures mostly form (Figure 2).

In the weld pool solidification proceeds from the already existing solid substrate and, therefore, formation of new nuclei is minor and negligible. Modifiers and dynamic methods, such as melt mixing in the weld pool and welding arc oscillations, are used to control nucleus growth. To describe the influence of these factors, heat and mass transfer models should be related to probabilistic models, such as cell automation or deterministic models with application of fundamental nucleation equations [9].

Microstructure formation during nucleus growth is controlled by the processes on the solid and liquid interface. Stability of this interface is determined by thermal conditions and chemical composition in the immediate vicinity of the interface. Depending on these conditions, linear, cellular (honeycomb) or dendritic crystal growth can proceed. Crystal growth in the heat flow direction is beneficial in terms of energy, that should be taken into account at prediction of weld metal microstructure [21].

As dendrite growth in the heat flow direction is the main mechanism of solidification in steel welding [20], it is rational to consider the models, describing exactly this process and possibilities of these models.

Dendrite growth simulation. Solidification process modeling is important for understanding phase transition phenomena that is why theoretical analysis and modeling of these processes have attracted scientists' attention for many decades. Considerable progress has been achieved in theoretical analysis of dendrite growth, as shown in the work by R. Trivedi and W. Kurz [22].

Most analytical models consider stationary growth of an isolated dendrite in the assumption that all the dendrites preserve the same shape. In this case the dendrite tip is considered to be a paraboloid of revolution [23].

At application of numerical methods to solve the problem of diffusion around the dendrites or a cellular dendrite tip, the assumption of a needle-like shape can be omitted, and it is also possible to take into account surface tension anisotropy on the liquid and solid interface [24].

At application of modern modeling methods, such as cell automation [25, 26] and phase fields [27], solidification morphologies can be modeled without any special assumptions of dendrite or cell shape.

Let us consider this subject in greater detail.

Dendrite stability. In [28] T. Koseki, based on theoretical analysis, showed that dendrites or cells form during solidification in a broad range of fusion welding conditions.

Dendrite structures form as a result of planar interface instability during solidification. Earlier, this phenomenon was explained by overcooling theory of W.A. Tiller and co-authors [29] and disturbance theory of W.W. Mullins and R.F. Sekerka [30]. At alloy solidification in planar interface mode, the region of overcooled melt ahead of this interface forms due to solute tran- 
sition from the solid state into the liquid phase. With increase of solute content, alloy melting temperature drops. Thus, if a disturbance appears on the solid and liquid interface, it can develop into a dendrite, the tip of which repulses the solute not only normal to solidification front, but also to the sides. In this connection, overcooling becomes smaller, compared to overcooling for planar interface. Theory of disturbances yields the lower and upper thresholds for solidification rate:

$$
\begin{gathered}
v_{\mathrm{s}}^{\min }=\frac{G D_{1}}{\Delta T_{0}}, \\
v_{\mathrm{s}}^{\max }=\frac{\Delta T_{0} D_{1}}{k \Gamma_{k}},
\end{gathered}
$$

where $G$ is the temperature gradient in liquid on the interface; $D_{1}$ is the coefficient of diffusion of the dissolved component in the melt; $\Delta T_{0}$ is the equilibrium cooling range; $k$ is the equilibrium coefficient of solute distribution; $\Gamma_{k}$ is the GibbsThomson coefficient.

For interstitial solutions such as alloys of $\mathrm{Fe}-\mathrm{C}$ system, at temperature gradient $G=2 \cdot 10^{4}{ }^{\circ} \mathrm{C} / \mathrm{m}$ typical for welding, threshold values of solidification rate can be calculated, proceeding from equations (1) and (2), being equal to $v_{\mathrm{s}}^{\min }=10^{-5}$ and $v_{\mathrm{s}}^{\max }=20 \mathrm{~m} / \mathrm{s}$ for steels. Thus, planar solidification mode is possible in welding, if the solidification rate is extremely low (of the order of $\mu \mathrm{m} / \mathrm{s}$ ), or extremely high (of the order of $\mathrm{m} / \mathrm{s}$ ). In most of the cases in practice, however, solidification rate is in the range of $v_{\mathrm{s}}^{\min }-v_{\mathrm{s}}^{\max }$. Initial solidification zone, located on the surface of weld pool contact with base metal, where solidification rate starts from zero, is an exception. Upper threshold of solidification rate is not achieved at regular fusion welding, as at increase of welding speed the weld pool takes the shape of a drop, and maximum solidification rate becomes close to a limited value, which is always smaller than the welding speed.

The above theoretical analysis of stability of planar solidification front shows that in welding of steels, solidification proceeds in the weld pool in the form of dendrites or cells. This emphasizes the importance of investigation and modeling of this kind of structures for understanding the welding phenomena.

Analytical models. Ivantsov's solution. The first sequential solution of the problem of diffusion around an isolated needle tip as that of crystal growth in an overcooled melt was published in [31] by G.P. Ivantsov. Isothermal surface around the dendrite tip was presented as joint paraboloid of revolution. Dendrite tip has the shape of paraboloid of revolution, as this corresponds to solid-liquid interface, which is considered to be isothermal. Analytical expression, connecting the radius of dendrite rounding-off $R_{\mathrm{t}}$ and growth rate $v_{\mathrm{t}}$ with dendrite tip temperature $T_{\mathrm{t}}$ presented in [31], is given in the following equation:

$$
\begin{gathered}
T_{\mathrm{t}}-T_{\infty}=\frac{\Delta H}{C_{m}} I v\left(\mathrm{Pe}_{\mathrm{t}}\right) ; \\
I v\left(\mathrm{Pe}_{\mathrm{t}}\right)=\mathrm{Pe}_{\mathrm{t}} \exp \left(\mathrm{Pe}_{\mathrm{t}}\right) \operatorname{Ei}\left(\mathrm{Pe}_{\mathrm{t}}\right) ; \quad \mathrm{Pe}_{\mathrm{t}}=\frac{v_{\mathrm{t}} R_{\mathrm{t}}}{2 \alpha},
\end{gathered}
$$

where $T_{\infty}$ is the melt temperature in the infinity; $\Delta H$ is the melting enthalpy; $C_{m}$ is the melt heat capacity; $I v$ is the Ivantsov's function; $\mathrm{Pe}_{\mathrm{t}}$ is the Peclet heat number; $E i$ is the integral exponential function; $\alpha$ is the thermodiffusion coefficient.

Having applied the analogy between thermal diffusion and solute diffusion, provided the dendrite tip composition is constant, a similar expression can be derived for concentrational dendrites:

$$
C_{\mathrm{t}}-C_{0}=C_{\mathrm{t}}(1-k) I v(\mathrm{Pe}) ; \quad \mathrm{Pe}=\frac{v_{\mathrm{t}} R_{\mathrm{t}}}{2 D_{\mathrm{l}}},
$$

where $C_{0}$ is the nominal composition of binary alloy; Pe is the Peclet concentration number.

For the specified temperature of the tip or its composition, the model predicts only the value of Peclet number or $v_{\mathrm{t}} R_{\mathrm{t}}$ product. It means that several variants of solution are possible for dendrites with tip radius inversely proportional to solidification rate.

In the case of limited directional solidification, the dendrite tip temperature is controlled by solute diffusion. Assuming that the phase diagram is linear, overcooling in the tip can be expressed by the formula

$$
\Delta T_{\mathrm{t}}=-m\left(C_{\mathrm{t}}-C_{0}\right),
$$

where $m$ is the inclination of liquidus line.

Substituting value $C_{\mathrm{t}}$ from equation (4) and allowing for the following relationship for equilibrium melting range $\Delta T_{0}=T_{\mathrm{t}}-T_{\mathrm{s}}=m C_{0}$ (1$-k) / k$, overcooling at dendrite tip can be written as

$$
\Delta T_{\mathrm{t}}=\frac{k \Delta T_{0} I v(\mathrm{Pe})}{1-(1-k) \operatorname{Iv}(\mathrm{Pe})} .
$$

If the solidification rate is determined by the process (for instance, type of heat source in welding), several solutions are available to determine overcooling at the dendrite tip. Thus, additional 
limitation is required to select a unique rounding-off radius of the dendrite from the multitude of possible solutions, predicted by Ivantsov's model.

Taking into account the influence of interphacial energy, equation (6) is modified into (7), which connects Ivantsov's model and stabilizing capillarity effect:

$$
\Delta T_{\mathrm{t}}=\frac{k \Delta T_{0} I v(\mathrm{Pe})}{1-(1-k) I v(\mathrm{Pe})}+\frac{2 \Gamma_{k}}{R_{\mathrm{t}}} .
$$

As Ivantsov's model is valid only for isothermal surfaces, and the capillarity effect is manifested only along nonisothermal surface, modifications of this model are only approximate. More detailed solutions for nonisothermal interfaces were suggested in [32, 33]. Addition of the capillarity term makes unstable only a very small area of solutions, but it does not eliminate the multiplicity of results predicted by Ivantsov's model. An additional limitation is required to allow the system to select a unique value of dendrite tip radius. As the ratio of rate and radii is of extreme nature, it was proved that selection of dendrite tip radius occurs at extreme value, which corresponds to maximum growth rate at a given overcooling or minimum overcooling at a given growth rate. It should be noted that experimental results, given in [34] by H.C. Huang and M.E. Glicksman, cast doubt on this assumption.

KGT-theory. Authors of work [35] J.S. Langer and H. Muller-Krumbhaar suggested replacing the maximum rate principle by form stability criterion $v_{\mathrm{t}} R_{\mathrm{t}}^{2}=$ const. They found that massive dendrites have an unstable tip, while those which are too narrow and rapidly growing, are, as a rule, slowed down, because of side branching instability. At present this is the most popular criterion of selection, called «limit stability». Proceeding from this concept, authors of $[23,36]$ developed a theoretical model for directional solidification, known as KGT-model. Assuming that dendrite tip radius in the stationary state is equal to critical wave length of unstable solidliquid interface $\left(R_{\mathrm{t}}=\lambda_{\mathrm{s}}\right)$ and using Ivantsov's solution for transportation problem, equations (8)-(11) were derived for the criterion of selection of dendrite tip parameters:

$$
\begin{gathered}
A v_{\mathrm{t}}^{2}-B v_{\mathrm{t}}+G=0, \\
A=\frac{\Gamma_{k}}{4 \sigma^{*} \mathrm{Pe}^{2} D_{\mathrm{l}}^{2}},
\end{gathered}
$$

$$
\begin{gathered}
B=\frac{k \Delta T_{0}}{1-(1-k) I v(\mathrm{Pe})} \frac{\xi}{D_{1}}, \\
\xi=1-\frac{2 k}{\left(1+\frac{1}{\sigma^{*} \mathrm{Pe}^{2}}\right)^{0.5}-1+2 k},
\end{gathered}
$$

where $\sigma^{*}$ is the stability constant, which is determined experimentally.

If we consider the critical wave length of unstable interface at dendrite tip $\lambda_{\mathrm{s}}$, then for it to correspond to planar interface, theoretical value of $\sigma^{*}$ should be equal to $1 / 4 \pi^{2}=0.0253$. Experimental values for different binary systems, which vary about value 0.02 [26], are in good agreement with this value.

For the specified value of solidification rate $v_{t}$, Peclet number Pe can be found by numerical solution of equation (8). Value of rounding-off radius $R_{\mathrm{t}}$ is derived from the expression for $\mathrm{Pe}$ (4). Using values Pe and $R_{\mathrm{t}}$, overcooling at dendrite tip and, therefore, temperature $T_{\mathrm{t}}$ can be calculated from equation (7), and composition at dendrite tip can be given by equation (4). Thus, the data, provided by KGT-model, can be used for comparison with predictions from other models, including variants of direct modeling of solidification.

KGT-model can be also used for calculation of dendrite growth kinetics through cell automation and virtual grain models, developed for direct modeling of grain structure formation in castings [37] and in welding [38].

Analytical modeling limitations. Above-described and similar [36] analytical models were focused on isolated dendrites, which grow either in overcooled melt, or in the melt with positive temperature gradient in constrained conditions of solidification. Problem of solidification with a free interface is extremely complex, and abovedescribed models are just an approximation to physical interpretation of the problem, in order to obtain a stable analytical solution. Their limitations consist in growth of dendrite bulk, in which diffusion fields of adjacent dendrites interact with each other. This is particularly evident in the impossibility of prediction of dendrite trunk spacing [39]. In addition, the above-considered analytical models do not describe the instability of dendrite tip, and, therefore, the development of dendrite secondary branches.

Numerical models. McCartney and Hunt models. Authors of work [24, 39] developed a theoretical model of stable growth of cell or dendrite bulk at positive temperature gradient using finite element methods. They proceeded from the 
fact that the problem with free interface and solid-liquid interface implies both phases being in equilibrium, as well as fulfillment of an additional condition of equilibrium on solid-liquid interface. This condition pertains to interface temperature $T_{\mathrm{i}}$ and its composition $C_{1}$, and curvature and kinetic mobility:

$$
T_{\mathrm{i}}=T_{M}+m\left(C_{1}-C_{0}\right)-\Gamma_{k} k-\frac{v}{\mu_{v}},
$$

where $v$ is the normal speed of interface movement; $\mu_{v}$ is the kinetic coefficient.

This numerical model eliminates the needle shape assumption. Moreover, diffusion of heat and solute are considered simultaneously. Thus, the model is capable of realistic predictions.

Derived numerical results point to a minimum of tip overcooling, depending on the half-width of an elementary cell. Form self-consistency can be found only under certain growth conditions [24], and only up to a certain maximum value of half-width. Assuming that the growth proceeds between minimum overcooling at the tip and point of instability, numerical results are in agreement with the respective experimental data. Here, no self-consistent form exists above a certain growth rate that makes application of this method impossible at transition from cellular to dendritic morphology with well-developed side branching, which cannot be modeled by this method.

Analysis by Hunt and Lu, interdentritic spacing and structure prediction. Using a modified variant of the above numerical model, J.D. Hunt and S.L. Lu [40] studied the mechanisms of spacing adjustment in the growing bulk of cells or dendrites. In order to make the analysis simpler and faster, they eliminated solution of heat conductivity equation. Instead, heat flow was described by introducing a moving linear temperature field, which varies only in the axial direction. In addition, a very simple model was developed for several cells, which studies the interactions of a central cell with six surrounding cells. This model was the basis to propose a criterion of selection of minimum distance to a stable cell. One of the most important model results is that it predicts a small range of distances to a stable cell and a separate range for dendrites.

The above results are generalized in [41], where numerical data in a dimensionless form were provided with analytical expressions for determination of concentratal overcooling and overcooling due to surface curvature («curvature under cooling») on the interface both for cellular solidification mechanism and for the dendritic one. Formulas, given in this work, are in good agreement with experiments and other models, as they represent dependencies of primary dendrite spacing, as well as overcooling at the tips for cells and dendrites bulk, depending on solidification parameters (rate, temperature gradient and material properties).

Spatial (direct) modeling methods. Direct modeling methods imply modeling of the entire dendrite structure or its significant part. For this purpose the solid and liquid phase evolution should be calculated in space and time. This can be implemented by explicit tracing of the interface, or implicitly, both in cell automation or in phase field model, which are described below.

Cellular automation. Brown model. Over the last two decades cellular automation was used for modeling various phase transformations in materials [42, 43]. This simulation method uses a regular grid, which is divided into cells of equal size, as a rule these are square in 2D and cubes in 3D. Each cell is characterized by its state, for instance, liquid phase, solid phase, phase 1, phase 2, etc. A cell can also contain one or several variables, for instance, values of temperature and/or composition. Applying the transition rules, a cell can change its state iteratively in time («stepping»). Transition rules allow for the state of the cell proper, its neighbours and their variables. This is a very simple method to study system evolutions in response to process parameters and variables. Theoretical and practical importance of application of cellular automation model for simulation of solidification phenomenon was considered in the works by S.G.R. Brown and J.A. Spittle [42], and Ch.-A. Gandin and M. Rappaz [37].

Illustration of application of cellurar automation modeling to simulate dendrite morphologies and growth kinetics was presented in [25]. The authors calculate unrestrained growth of nonisothermal dendrites in overcooled melts for single-component systems. The model includes rules to allow for thermal diffusion, curvature impact on equilibrium solidification temperature and latent heat evolution. Predicted growth kinetics is in good agreement with the known experimental and theoretical results. However, as quantitative physics of the process is practically not included into the model, this model allows only a qualitative study of the factors determining dendrite development in overcooled melts.

Sasikumar-Sreenivasan model. Work [26] presents a 2D-model of dendrite growth in a single-component system with elements of cell automation method, similar to S.G.R. Brown model 

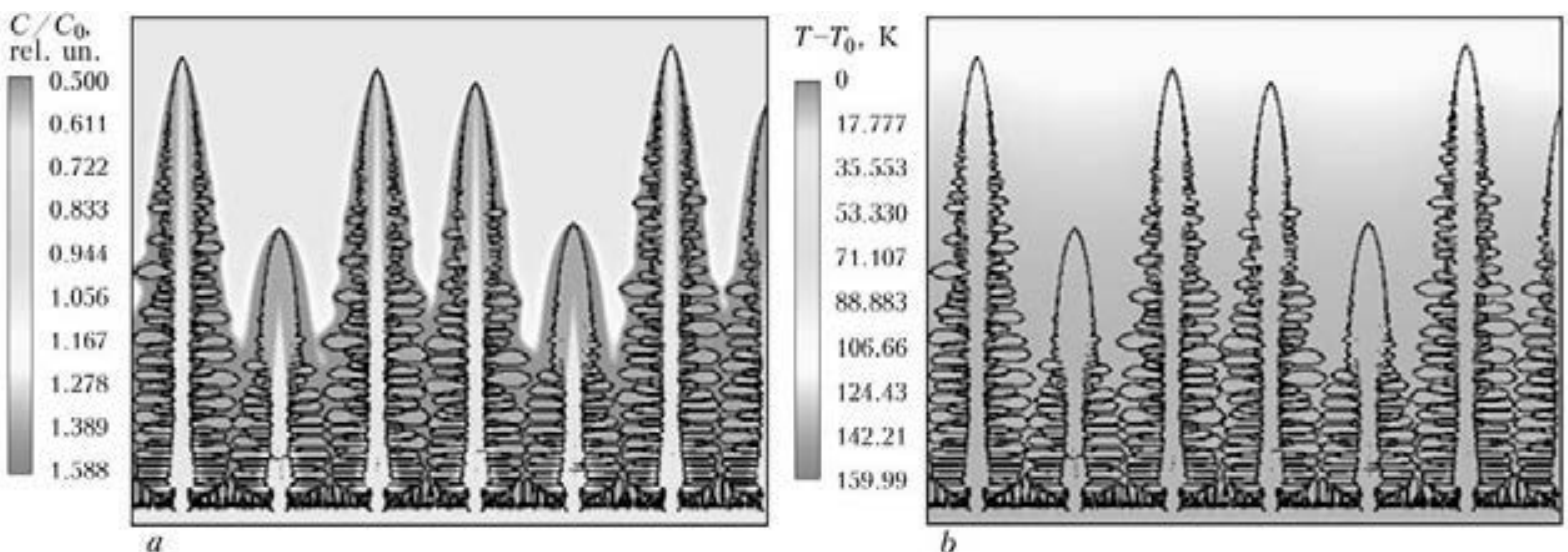

Figure 3. Result of modeling oriented dendrite growth in overcooled $\mathrm{Fe}-\mathrm{C}$ melt [49]: $a-$ concentration distribution $C / C_{0} ; b$ - temperature distribution $T-T_{0}$

described above, but expanded with finite element method to solve heat conductivity equations. Thus, Sasikumar-Sreenivasan model is a combination of physical and empirical approaches, i.e. moving force of dendrite growth is calculated on the basis of realistic physical model, whereas empirical rules, introduced into this method, are used to allow for surface curvature, growth anisotropy and noise. One cannot expect that the model will yield quantitatively correct results, but it can be used to study the tendencies in dendrite morphology variation, depending on material properties and process parameters.

In more recent studies this model was modified to illustrate particle influence on dendrite morphology [44] and for modeling in binary alloys [45].

Results of Galenko and Krivilev. This approach was used in [46-49] and showed adequate results in modeling dendrite growth (Figure 3) both at low rates of crystal growth (diffusionlimited solidification), and for high-rate growth (diffusion-limited and kinetically controlled solidification). Moreover, work [46] gives a number of results for various alloys $(\mathrm{Fe}-\mathrm{C}, \mathrm{Cu}-\mathrm{Ni}$, $\mathrm{Ni}-\mathrm{B}, \mathrm{Ag}-\mathrm{Cu}$ ).

Phase field method. Over the last years, the popularity of phase field method has been rapidly rising [27, 50, 51]. The method is based on fundamental physical principles from thermodynamics and kinetics, and is widely applied for modeling a wide range of phase transition problem. The main principles of the method and its application to solidification problem can be described on the basis of [27], in which Steinbach model [52] was adapted for phase transformations in steels, in particular, for growth of dendrites with peritectic reaction, grain growth and allotriomorphous formation of ferrite.

Phase field method rejects the paradigm of a clear-cut interface, introducing parameter $\varphi$, which points to the presence $(\varphi=1)$ or absence $(\varphi=0)$ of a certain phase [27]. On the interface parameter $\varphi$ changes abruptly, but not continuously in several points of the grid. Real position of the interface is assumed to be in the point where $\varphi=0.5$. Physical values are order parameter functions. Proceeding from minimizing system free energy functional, evolution equations are derived for various phases. In these equations overcooling for each phase pair is included as functions of solute local concentration. In the considered model [27], concentration is treated as an external filed, and diffusion equations are reduced to $\varphi$. Thus, modeling of microstructural evolution at phase transformations associated with a set of non-linear differential equations for phase $\varphi$ and concentration fields has a numerical solution.

As phase field models deal with numerical solution of differential equations, they can be easily configured both in 2D and in 3D [53]. Calculations, however, are very intensive.

Despite the fact that they should yield quantitative results, their application for modeling the processes in currently available materials requires knowledge of material physical properties, which are difficult to determine. This method, however, is becoming one of the most powerful and promising in the field of modeling phase transitions in different systems.

In conclusion it should be noted that solidification in the weld pool is the first stage of microstructure formation in fusion welding, which influences the final microstructure and, therefore, mechanical and technological properties of the weld. The main parameters governing this process are alloy composition, solidification rate and temperature gradient ahead of solidification front.

In order to allow for the influence of nonmetallic inclusions on the primary structure, and, hence, on the secondary one, dendrite growth in the weld pool during cooling should be modeled. 
Considerable success has been achieved in the field of analytical modeling of dendritic structures, which, in principle, is applicable to welding. Analytical models, however, are limited to consideration of isolated dendrite tips. Interaction between diffusion fields of adjacent dendrites is ignored. Moreover, interdendrite spacing can be very roughly predicted and with a number of empirical assumptions that does not allow making qualitative predictions of metal dendrite structure in a situation, when the weld pool contains various nonmetallic inclusions.

Numerical methods of modeling concentration field propagation around the tip of a dendrite or cell allow more accurate description of needle shape, overcooling and concentration as functions of growth conditions and material properties.

Analytical and numerical models of dendrite growth do not allow for the possibility of branching, structure coarsening and microsegregation in the entire two-phase zone, as they assume complete symmetry and describe only the interface.

Direct modeling methods, such as cell automation and phase field method, potentially do not need any limitations, and are capable of simulating the entire structure during solidification. Their application allows obtaining temperature or concentration fields ahead of solidification front, dendrite tip geometry, primary and secondary spacing between dendrite branches, as well as microsegregations in partially melted zone. However, as these methods are based on numerical solutions of the main equations and/or transition rules, dimensional effect should be studied and minimized.

Positive result of application of these models to solve practical problems can be achieved in the case, when direct modeling methods are based on the results derived using analytical and numerical models.

The above-said leads to the conclusion that the most adequate and characteristic results of dendrite growth modeling, allowing for the influence of nonmetallic inclusions, can be expected from cell automation method, which should be modified to allow for the capabilities of analytical and numerical models. The advantage of this method, compared to phase field method, consists in its computational simplicity and no need for determination of some physical properties of real materials, such as mobility or anisotropy.

1. David, S.A., Babu, S.S., Vitek, J.M. (2001) Recent advances in modeling and characterization of weld microstructure. Sci. and Techn. of Welding and Joining, 6(6), 341-346.
2. Santella, M.L., Babu, S.S., Riemir, B. et al. (1999) Trends in welding research. In: Proc. of 5th Int. Conf. Materials Park: ASM Int., 605-609.

3. Grong, O. (1997) Metallurgical modeling of welding. London: TIM.

4. Joensson, P.G., Szekely, J., Choo, R.T.T. et al. (1994) Mathematical models of transport phenomena associated with arc-welding processes: A survey. Modeling and Simulation in Material Sci. and Eng., 2, 995-1016.

5. Evans, G.M., Bailey, N. (1997) Metallurgy of basic weld metal. Abington: Woodhead Publ.

6. Kluken, A.O., Grong, O. (1989) Mechanisms of inclusion formation in $\mathrm{Al}-\mathrm{Ti}-\mathrm{Si}-\mathrm{Mn}$ deoxidized steel weld metals. Metallurg. Transact. A, 20, 1335-1349.

7. Hseih, K.C., Babu, S.S., Vitek, J.M. et al. (1996) Calculation of inclusion formation in low alloy steel welds. Mat. Sci. Eng. A, 215, 84-91.

8. Koseki, T., Ohkita, S., Yurioka, N. (1997) Thermodynamic study of inclusion formation in low alloy steel weld metals. Sci. and Techn. of Welding and Joining, 2, 65-69

9. Babu, S.S., David, S.A., Vitek, J.M. et al. (1995) Development of macro- and microstructures of $\mathrm{C}-\mathrm{Mn}$ low alloy steel welds - inclusion formation. Mat. Sci. and Techn., 11, 186-199.

10. Babu, S.S., Raidebach, F., David, S.A. et al. (1999) Effect of high-energy-density welding processes on inclusion and microstructure formation in steel welds. Sci. and Techn. of Welding and Joining, 4, 63-73.

11. Manson, P. (2012) Program AIDS in modeling welding thermodynamics. Welding J., 12, 28-30.

12. Andersson, J.O., Helander, T., Hoeglund, L. et al. (2002) Thermo-calc and DICTRA, computational tools for materials science. CALPHAD., 26, 273-312.

13. Babu, S.S. (2009) Thermodynamic and kinetic models for describing microstructure evolution during joining of metals and alloys. Int. Mat. Rev., 54(6), 333-367.

14. Babu, S.S., Vitek, J.M., Iskander, Y.S. et al. (1997) New model for prediction of ferrite number of stainless steel welds. Sci. and Techn. of Welding and Joining, 2(6), 279-285.

15. Vitek, J.M., Iskander, Y.S., Oblow, E.M. (2000) Improved ferrite number prediction in stainless steel arc welds using artificial neural networks. Pt 1: Neural network development. Welding J., 79(2), 33-46.

16. Bhadeshia, H.K.D.H., Svensson, L.E., Gretoff, B.A. (1985) A model for the development of microstructure in low-alloy steel $(\mathrm{Fe}-\mathrm{Mn}-\mathrm{Si}-\mathrm{C})$ weld deposits. Acta Metall., 33, 1271-1283.

17. Ion, J.C., Easterling, K.E., Ashby, M.F. (1984) A second report on diagrams of microstructure and hardness for heat-affected zones in welds. Ibid., 32(11), 1949-1962.

18. Kasuya, T., Yurioka, N. (1993) Carbon equivalent and multiplying factor for hardenability of steel. Welding J., 72, 263-268.

19. Smallman, R.E., Bishop, R.J. (1999) Modern physical metallurgy and materials engineering. Oxford: Butterworth-Heinemann Publ.

20. Pavlyk, V. (2004) Modeling and direct numerical simulation of dendritic structures under solidification conditions during fusion welding. Aachen: Shaker.

21. David, S.A., Babu, S.S., Vitek, J.M. (2003) Welding: Solidification and microstructure. http:// www.tms.org / pubs/journals/JOM/0306/David-0 306.html

22. Trivedi, R., Kurz, W. (1994) Dendritic growth. Int. Mat. Rev., 39(2), 47-74.

23. Kurz, W., Giovanola, B., Trivedi, R. (1986) Theory of microstructure development during rapid solidification. Acta Metall., 34(5), 823-830.

24. McCartney, D.G., Hunt, J.D. (1984) A numerical finite difference model of steady state cellular and dendritic growth. Metallurg. Transact. A, 15, 983-994. 
25. Brown, S.G.R., Williams, T., Spittle, J.A. (1994) A cellular automaton model of the steady-state «free» growth of a non-isothermal dendrite. Acta Metall. et Mat., 42(8), 2893-2898.

26. Sasikumar, R., Sreenivasan, R. (1994) 2-dimensional simulation of dendrite morphology. Ibid., 2(7), 2381-2386

27. Tiaden, J., Grafe, U. (1999) A phase-field model for diffusion and curvature controlled phase transformations in steels. In: Proc. of Int. Conf. on Solid-Solid Phase Transformations (Kyoto, Japan, 1999), 737-740.

28. Koseki, T. (2001) Solidification and solidification structure control of weld metals. Welding Int., 16(5), 347-365.

29. Tiller, W.A., Jackson, K.A., Rutter, J.W. et al. (1953) The redistribution of solute atoms during the solidification of metals. Acta Metall., 1, 428-437.

30. Mullins, W.W., Sekerka, R.F. (1964) Stability of a planar interface during solidification of a dilute binary alloy. J. Appl. Phys., 35(2), 444-451.

31. Ivantsov, G.P. (1947) Temperature field around spherical, cylindrical and needle-like crystal growing in supercooled melt. Doklady AN SSSR, 58(4), 567-569.

32. Temkin, D.E. (1960) On rate of crystal needle growing in supercooled melt. Ibid., 132(6), 1307-1310.

33. Trivedi, R. (1970) Growth of dendritic needles from a supercooled melt. Acta Metall., 18(3), 287-296.

34. Huang, H.C., Glicksman, M.E. (1981) Fundamentals of dendritic solidification: Steady-state tip growth. Ibid., 29, 701-715.

35. Langer, J.S., Mueller-Krumbhaar, H. (1977) Stability effects in dendritic crystal growth. J. Crystal Growth, 42, 11-14

36. Kurz, W., Fisher, D.J. (1992) Fundementals of solidification. TransTech Publ.

37. Gandin, Ch.-A., Rappaz, M. (1994) A coupled finite element-cellular automaton model for the prediction of dendritic grain structures in solidification processes. Acta Metall., 42(7), 2233-2246.

38. Ploshikhin, V.V., Bergmann, H.W. (2001) Correlation between the welding parameters and the grain structure for the fast moving high power line heat source in a thin plate. In: Mathematical modeling of weld phenomena 5. London: IOM Commun., 269-281.

39. Hunt, J.D., McCartney, D.G. (1987) Numerical finite difference model for steady state cellular array growth. Acta Metall., 35, 89-99.

40. Lu, S.L., Hunt, J.D. (1992) A numerical analysis of dendritic and cellular array growth: The spacing adjustment mechanisms. J. Crystal Growth, 123, 17-34.
41. Hunt, J.D., Lu, S.L. (1996) Numerical modeling of cellular/dendritic array growth: Spacing and structure predictions. Metallurg. and Mat. Transact. A, 27(3), 611-623.

42. Spittle, J.A., Brown, S.G.R. (1994) A 3D cellular automaton model of coupled growth in two component systems. Acta Metall. et Mat., 42(6), 1811-1815.

43. Dilthey, U., Reichel, T., Pavlik, V. (1997) A modified cellular automaton model for grain growth simulation. In: Mathematical modeling of weld phenomena 3. London: Maney Publ., 106-113.

44. Kurien, L., Sasikumar, R. (1996) Simulation of dendrite morphology in the presence of particles. Acta Metall., 44(8), 3385-3395.

45. Sasikumar, R., Jacob, E., George, B. (1998) Simulation of dendrite growth in binary alloys. Scripta Mat., 38(4), 693-701.

46. Galenko, P.K., Krivilev, M.D. (2000) Isothermal growth of crystals in supercooled binary alloys. Mat. Modelirovanie, 12(11), 17-37.

47. Galenko, P.K., Krivilev, M.D. (2000) Finite-difference scheme for modeling of crystal structure formation in supercooled binary alloys. Ibid., 12(12), 11-23.

48. Krivilev, M.D., Galenko, P.K. (2008) Modeling of transition to diffusionless solidification in high-speed crystallization of binary alloys. Vestnik UdmurtGU, 1, 129-140.

49. Krivilev, M.D., Galenko, P.K. (1999) Software complex for modeling of crystal structure formation in supercooled binary alloys: Manual. Izhevsk: UdmurtGU.

50. Zhang, Y. (2012) Phase field modeling of dendritic growth and coarsening supercooling. http://Www. intechopen.com/books/supercoo-ling/phase-fieldmodeling-of-dendritegrowth

51. Lebedev, V.G., Danilov, D.A., Galenko, P.K. (2010) On equations of phase field model for non-isothermal kinetics of transformations in multicomponent and multiphase system. Vestnik UdmurtGU, 1, 26-33.

52. Steinbach, I., Pezzolla, F., Nestler, B. et al. (1996) Phase field concept for multiphase systems. Physica D: Nonlinear Phenomena, 94(3), 135-147.

53. Kobayashi, R.A. (1994) A numerical approach to three-dimensional dendritic solidification. Exp. $\mathrm{Ma}$ thematics, 3, 410-423. 